\title{
Integration of deep geothermal energy and woody biomass conversion pathways in urban systems*
}

\author{
Stefano Moret ${ }^{\dagger 1}$, Emanuela Peduzzi ${ }^{1}$, Léda Gerber $^{2}$, and François Maréchal ${ }^{1}$ \\ ${ }^{1}$ Industrial Process and Energy Systems Engineering (IPESE), École Polytechnique \\ Fédérale de Lausanne \\ ${ }^{2}$ Department of Chemical and Biomolecular Engineering, Cornell University, Ithaca, \\ New York 14853, United States and Cornell Energy Institute, 2160 Snee Hall, Cornell \\ University, Ithaca, New York 14853, United States
}

July $8^{\text {th }}, 2016$

\begin{abstract}
Urban systems account for about two-thirds of global primary energy consumption and energy-related greenhouse gas emissions, with a projected increasing trend. Deep geothermal energy and woody biomass can be used for the production of heat, electricity and biofuels, thus constituting a renewable alternative to fossil fuels for all end-uses in cities: heating, cooling, electricity and mobility. This paper presents a methodology to assess the potential for integrating deep geothermal energy and woody biomass in an urban energy system. The city is modeled in its entirety as a multiperiod optimization problem with the total annual cost as an objective, assessing as well the environmental impact with a Life Cycle Assessment approach. For geothermal energy, deep aquifers and Enhanced Geothermal Systems are considered for stand-alone production of heat and electricity, and for cogeneration. For biomass, besides direct combustion and cogeneration, conversion to biofuels by a set of alternative processes (pyrolysis, Fischer-Tropsch synthesis and synthetic natural gas production) is studied. With a scenario-based approach, all pathways are first individually evaluated. Secondly, all possible combinations between geothermal and biomass options are systematically compared, taking into account the possibility of hybrid systems. Results show that integrating these two resources generates configurations featuring both lower costs and environmental impacts. In particular, synergies are found in innovative hybrid systems using excess geothermal heat to increase the efficiency of biomass conversion processes. The application to a case study demonstrates the advantages of using a system approach for the analysis over a stand-alone comparison between options.
\end{abstract}

Keywords: Geothermal energy, Woody biomass conversion, Urban energy systems, Energy modeling, Optimization, Life Cycle Assessment (LCA)

\footnotetext{
*Electronic Supplementary Information (ESI) available. $\ddagger$ indicates a reference to the ESI in the main article.

${ }^{\dagger}$ stefano.moret@epfl.ch
}

This is the pre-print (submitted) version of the paper. Published version: Moret S, Peduzzi E, Gerber L, Maréchal F, Integration of deep geothermal energy and woody biomass conversion pathways in urban systems. Energy Conversion and Management 2016; 129:305-318. DOI: http://dx.doi.org/10.1016/j.enconman.2016.09.079. 


\section{Introduction}

To mitigate the projected catastrophic effects of climate change, the "2DS" scenario, which aims at an $80 \%$ chance of limiting the increase of the global average temperature below $2{ }^{\circ} \mathrm{C}$ compared to pre-industrial levels, envisions a $50 \%$ reduction of greenhouse gas (GHG) emissions compared to 2011 levels [1]. Fossil fuels account for more than $80 \%$ of the world primary energy supply [2] and for the majority of anthropogenic GHG emissions. Thus, substitution of fossil fuels with renewable energy sources, such as geothermal and biomass, is one of the key actions to tackle climate change. In 2008, geothermal energy and bioenergy accounted for $0.1 \%$ and $10.2 \%$ of global primary energy supply, respectively. Within bioenergy, woody biomass had the largest share [3]. Based on 2003 data, the worldwide use of biomass has been estimated to be $38 \%$ of the global potential [4]. Bioenergy demand is expected to increase at least threefold by 2050 [3]. Geothermal energy is projected to cover $3.5 \%$ of the global electricity production and $3.9 \%$ of the final energy for heat in the same year [5].

As of 2014, $54 \%$ of the world population lived in urban areas, a figure expected to rise to $66 \%$ by 2050 [6]. Urban systems account for about two-thirds of global primary energy consumption and for $71 \%$ of global energy-related GHG emissions [7]. Heating, cooling, electricity and mobility are the four components of urban systems final energy consumption. Deep geothermal energy $^{1}$ and woody biomass are widely available renewable resources and represent a promising alternative to fossil fuels to meet this demand. Although often only considered for electricity production [9], deep geothermal energy can provide baseload supply in heating dominated urban energy systems for low temperature heating requirements, which constitute the largest share of heat demand [10], whereas biomass can be used for higher temperatures and peaks. The high heat density in cities makes the deployment of District Heating Networks (DHNs) more economically competitive [11]. DHNs are necessary in order to integrate large-scale renewables (such as deep geothermal wells) and cogeneration systems for heat supply [12]. Additionally, contextualizing the comparison among different technology options within urban energy models presents the advantage of defining a reference state of the energy system, taking into account the structure and seasonal variation of the demand, and the existing and competing technologies. This system approach captures the complexity deriving from the interaction between the different energy sectors [13], such as the penetration of electric technologies for heating and mobility end-uses.

\section{$1.1 \quad$ State of the art}

\subsubsection{Geothermal energy and biomass in urban systems}

In the literature, most studies focus on a stand-alone comparison of energy conversion pathways. As an example, biomass-to-fuel optimal strategies can be identified based on the framework presented by Kim et al. [14]. The contextualization of technology assessment within energy systems, in particular at the urban level, has emerged in the last years [13].

Gerber et al. [15] have applied multi-objective optimization for the evaluation of deep geothermal and biomass (direct combustion in boiler and gasification) integration in an urban system taking into account total yearly cost and Global Warming Potential (GWP) with a Life Cycle Assessment (LCA) approach. The urban system is modeled in its entirety (only decentralized heating is excluded) and one year is broken down into a set of independent periods with different heating and electricity requirements. Results show that geothermal solutions can reduce both total annual costs and global GHG emissions, as well as the interest of converting wood

\footnotetext{
1 "Deep geothermal energy" is here used for resources of depth greater than $1000 \mathrm{~m}$ and temperatures exceeding $60{ }^{\circ} \mathrm{C}[8]$.
} 
to Synthetic Natural Gas (SNG) for use in mobility. The work highlights how results strongly depend on the integration within urban systems. Alberg Østergaard et al. [16] have applied the EnergyPLAN model [17] to design a $100 \%$ renewable scenario for a Danish city for the year 2050, mostly based on biomass, geothermal and wind power. Low-depth resources combined with absorption heat pumps are considered for geothermal, whereas the quantity of biomass previously dedicated to individual residential heating is converted to produce biogas and SNG. Results show a lower total cost of the future energy system compared to the reference scenario, although with a much higher investment-to-fuel cost ratio.

In these works only a subset of the possible energy conversion pathways is considered, and no possibility for heat integration between geothermal and biomass technologies is taken into account. Other studies focus only on one of the two resources. As an example, Sommer et al. [18] have assessed the economics of geothermal district heating for a community in California. Vallios et al. [19] have proposed a methodology for the design of biomass district heating systems, whereas Pantaleo et al. [20] have developed an approach to design optimal biomass supply chains for heat and power generation in urban areas.

\subsubsection{Hybrid geothermal-biomass systems}

Integration and hybridization with geothermal and solar resources have been identified as a strategic research priority for biomass in Europe [21]. Hybrid geothermal-biomass systems are here defined as energy conversion systems coupling the two resources. Hybridization has been applied to the production of electricity in Organic Rankine Cycles (ORCs), with geothermal heat used for biomass drying and preheating, and biomass supplying the remaining heat requirements at higher temperature. This is the case for an existing $35.5 \mathrm{MW}_{\mathrm{e}}$ installation in California, USA [22]. Borsukiewicz-Gozdur [23] has proposed a hybrid ORC concept using two working fluids. Thain and DiPippo [24] have recently explored different interesting configurations for hybrid geothermal-biomass power plants.

These hybridization pathways focus on electricity production cycles, showing the possibility of achieving higher efficiencies by combining the two resources.

\subsubsection{Integration of hybrid solutions in urban systems}

Integration of hybrid solutions in urban energy systems has been recently explored. Kilkis [25] has proposed a hybrid lignite-geothermal plant for a district energy system and hydrogen production facility for a Turkish city. A wider energy system integration, also taking into account the seasonal variations of the demand, has been proposed for the Cornell University campus (USA)[26]: a hybrid geothermal-natural gas-biomass conversion system in which geothermal energy is used in combination with biomass for heat production, and excess geothermal heat is used for electricity production with an ORC during periods of low heating demand. In these works there is no hybridization at the level of the energy conversion processes, as the two resources contribute separately to the energy services supply in the district. The case study at Cornell has been recently widened by Beckers et al. [27], including the hybrid option of using geothermal heat for biomass drying prior to gasification. Malik et al. [28] studied a multigeneration biomass-geothermal system to produce heating, cooling and electricity for cities, and liquified gas and drying for industrial processes. In a case study evaluating different options for the integration of geothermal energy in the urban system of Lausanne (Switzerland), Amblard [29] highlights that the availability of geothermal heat in summer surpasses the demand. A preliminary case study to this paper [30], in which options for woody biomass conversion have been added to the same case study, has shown the interest of using this excess of geothermal heat in summer for integration in the biomass drying process: the storage of geothermal energy 
in form of dry wood for combustion in winter allowed a complete replacement of fossil fuels for the district heating network supply. In this preliminary case study only a subset of options was considered and the LCA analysis was limited to the GWP indicator.

Thus, the main gaps identified in the literature are i) the consideration of only part of the urban system and ii) of a subset of energy conversion pathways for deep geothermal and biomass. This specificity implies that iii) optimization of the overall urban system is seldom performed. Furthermore $i v$ ) hybrid options are often evaluated stand-alone and not integrated in urban systems, and v) LCA analysis is limited to the GWP impact assessment method.

\subsection{Purpose of the study}

Consequently, we present a methodology for evaluating the potential benefits of deep geothermal and woody biomass integration in urban energy systems. To achieve this $i$ ) a model is developed for the entire urban energy system with the appropriate level of detail for the analysis. ii) Multiple options are considered for the resources: deep aquifers and Enhanced Geothermal System (EGS) for deep geothermal; drying, combustion in boilers and cogeneration engines, pyrolysis, gasification, Fischer-Tropsch (FT) for woody biomass. iii) The model is formulated as a multi-period Mixed-Integer Linear Programming (MILP) problem and $i v$ ) the use of process integration [31] ensures accounting for hybridization possibilities. Furthermore, v) The LCA analysis is extended to include human health impact assessment methods along with global warming potential.

The developed methodology is illustrated by an application case study. The city of Lausanne (Switzerland, 140,421 inhabitants in 2015) is taken as an example case study in this work. It has an existing DHN supplying a significant share of the heating final energy demand. The projected expansion of the DHN offers an opportunity for the integration of renewable energy. The case study is presented in the Supplementary Information (ESI ${ }^{\ddagger}$, Section 1).

First the methodology is presented, with the definition of the urban system MILP model, the performance indicators and the scenario-based approach (Section 2). The options for deep geothermal and biomass are first individually assessed and then systematically combined in order to explore the possible synergies. Scenario results are analyzed with a particular focus on interesting synergies between the two renewable resources (Section 3), with the goal of identifying the most promising strategies for urban systems planning.

\section{Methodology}

Figure 1 offers an overview of the scenario-based methodology, whereas the following subsections describe in detail the different steps. First, the MILP urban energy system model is developed. The model represents the superstructure common to all scenarios, i.e. it is a general formulation including all the possible investigated pathways. Based on this general framework, a scenario is defined by a set of additional constraints fixing the use or the size of the corresponding resources or technologies. For each scenario, the optimal solution in terms of total cost is identified, and LCA indicators for GWP and human health are calculated.

The methodology is implemented in the OSMOSE calculation platform [32], using AMPL [33] for the definition of the mathematical programming problem and CPLEX 12.6.1.0 as a solver. Extensive documentation of the methodology and of the technology models in the ESI ${ }^{\ddagger}$ allows reproducibility and application to different case studies and technologies. 


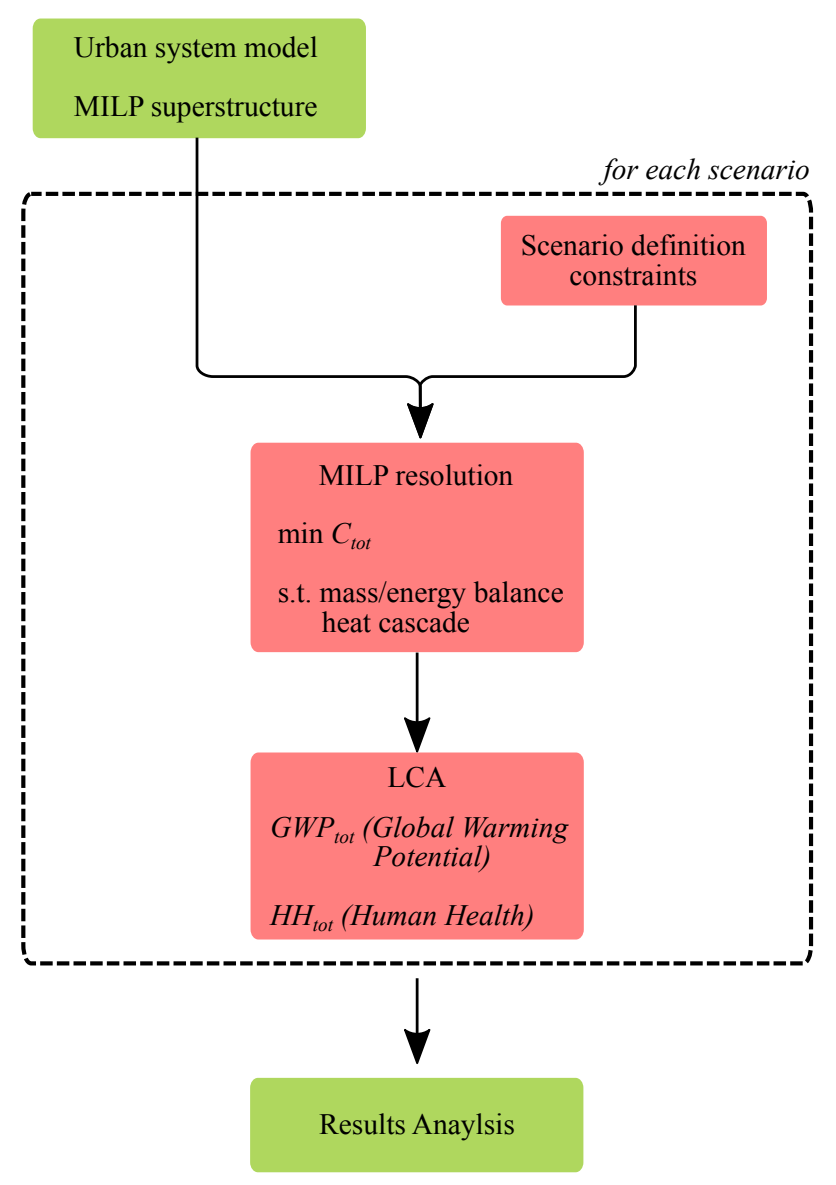

Figure 1: Overview of the scenario-based methodology

\subsection{Urban energy system model}

An urban energy system model has been defined as "a formal system that represents the combined processes of acquiring and using energy to satisfy the energy service demands of a given urban area" [13]. Thus, it is a simplified representation of an urban system accounting for the energy flows within its boundaries. The urban energy system model developed for this work is depicted in Figure 2.

The urban energy system is modeled in its entirety. Imported and indigenous resources can be converted with energy conversion technologies to satisfy end-use demand in energy services: heat, mobility (private and public) and electricity. Cooling is not accounted for in this work. Heat production is separated into centralized and decentralized. Geothermal and biomass options are considered for centralized heat production together with existing technologies such as boilers, a Waste Water Treatment Plant (WWTP) and a Municipal Solid Waste Incinerator (MSWI). A DHN delivers the produced heat to the consumers. A multiperiod formulation dividing the year in four periods (winter, mid-season, summer, peak) is adopted in order to account for seasonality. Storage across periods is allowed for certain resources. All the unit models and their adaptation to the Lausanne case study are described in detail in the ESI ${ }^{\ddagger}$ (Section 3).

Each resource or technology model corresponds to a "unit". Each unit has inputs and outputs, 


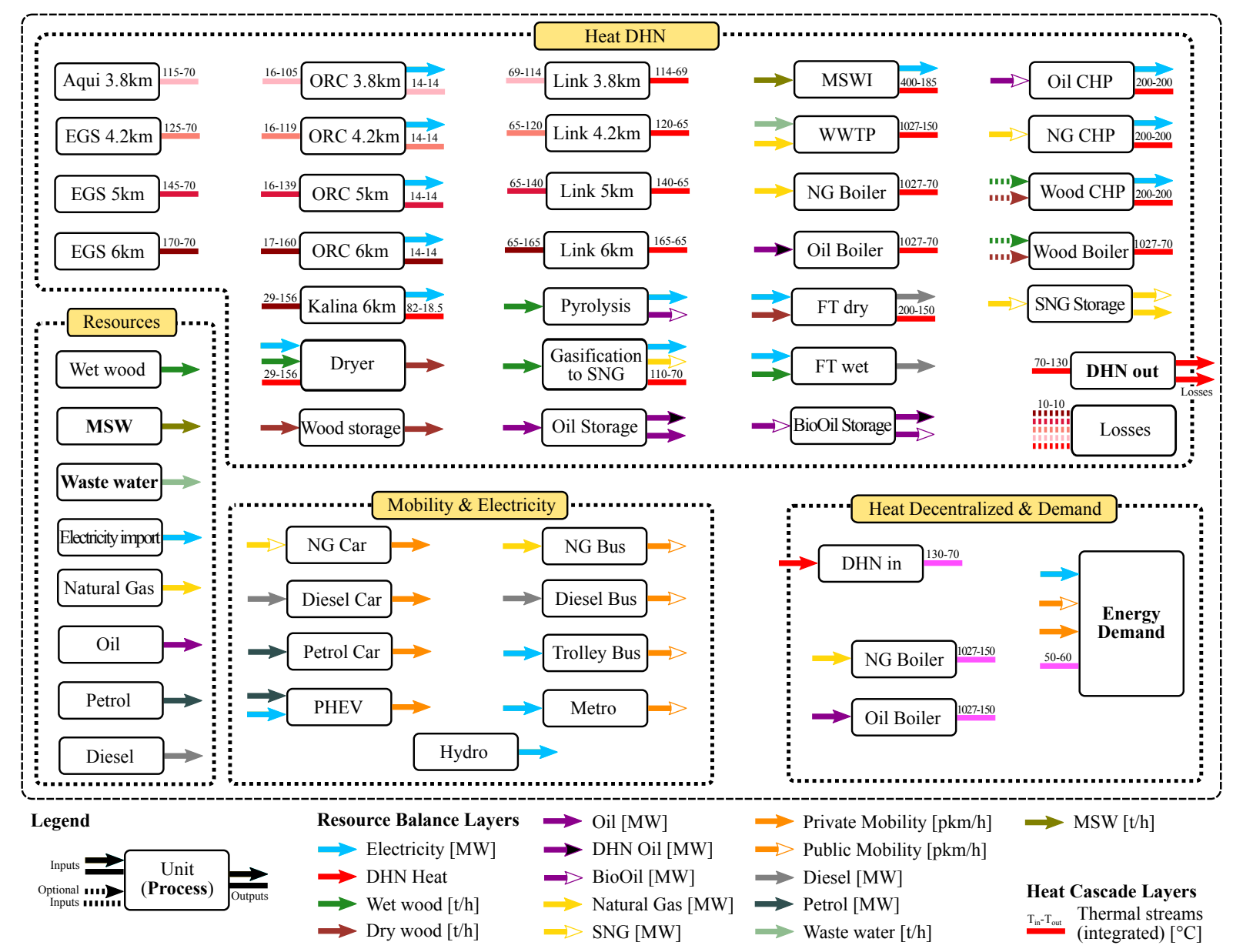

Figure 2: Urban energy system model.

which are associated with two types of "layers": "Resource Balance" and "Heat Cascade". Each layer of type "Resource Balance" corresponds to a mass flow or power balance in the entire system. As an example, all the diesel imported or produced by the Fischer-Tropsch units needs to be consumed by the units having this resource as an input. Thermal streams belong to the "Heat Cascade" layers. To simplify the representation, for units with multiple thermal streams only the net heating requirement or excess are shown in Figure 2 . Thermal streams can exchange only with other streams belonging to the same heat cascade layer, while "linking" units can be used to connect different heat cascade layers. In the case of geothermal, for example, the use of different heat cascades allows the option of either directly supplying the district heating network or producing electricity with an ORC or Kalina cogeneration cycle.

\subsection{MILP model formulation}

This section details the constraints of the MILP model. The MILP formulation is based on the work by Maréchal and Kalitventzeff [31], later extended to include time-dependency [34] and mass balances [15]. The multiperiod storage formulation is a novelty of this work. Sets, parameters and variables of the MILP model with their relative indexes are reported in the $\mathrm{ESI}^{\ddagger}$ (Section 2). 
$\min \mathbf{C}_{\mathbf{t o t}}=\sum_{u \in U}\left(\mathbf{C}_{\mathbf{i n v}}(u)+\sum_{t \in T} \mathbf{C}_{\mathbf{o p}}(u, t)\right)$

s.t. $\operatorname{Use}_{\mathbf{t}}(u, t) \geq u s e_{f}(u, t)$

$f_{\min }(u) \mathbf{U s e}_{\mathbf{t}}(u, t) \leq \mathbf{M u l t}_{\mathbf{t}}(u, t) \leq f_{\max }(u) \mathbf{U s e}_{\mathbf{t}}(u, t)$

$\forall u \in U, \forall t \in T(2)$

$\mathbf{U s e}_{\mathbf{t}}(u, t) \leq \mathbf{U s e}(u)$

$\operatorname{Mult}_{\mathbf{t}}(u, t) \leq \operatorname{Mult}(u)$

$\mathbf{C}_{\text {inv }}(u)=c_{\text {inv,fix }}(u) \mathbf{U s e}(u)+c_{\text {inv,var }}(u) \operatorname{Mult}(u)$

$\mathbf{C}_{\mathbf{o p}}(u, t)=\left(c_{o p, f x}(u) \mathbf{U s e}_{\mathbf{t}}(u, t)+c_{o p, v a r}(u) \mathbf{M u l t}_{\mathbf{t}}(u, t)\right) t_{o p}(t)$

$\forall u \in U, \forall t \in T(3)$

$\forall u \in U, \forall t \in T(4)$

$\forall u \in U, \forall t \in T(5)$

$\forall u \in U(6)$

$\operatorname{Mult}_{\mathbf{s}}(s, t)=\operatorname{Mult}_{\mathbf{t}}(u, t)$

$\forall u \in U, \forall t \in T(7)$

$\sum c p(s, t) \mathbf{M u l t}_{\mathbf{s}}(s, t)\left(T_{i n}^{*}(s, t)-T_{\text {out }}^{*}(s, t)\right)-\sum c p(s, t) \mathbf{M u l t}_{\mathbf{s}}(s, t)\left(T_{\text {out }}^{*}(s, t)-T_{\text {in }}^{*}(s, t)\right)+$

$\sum_{s \in S_{H O T}(l, t) \mid T_{\text {out }}^{*}(s, t) \geq T_{\text {int }}(l, t, k)+\delta} \quad s \in S_{C O L D}(l, t) \mid T_{\text {in }}^{*}(s, t) \geq T_{\text {int }}(l, t, k)+\delta$

$\sum c p(s, t) \mathbf{M u l t}_{\mathbf{s}}(s, t)\left(T_{i n}^{*}(s, t)-T_{\text {int }}(l, t, k)\right)-\sum c p(s, t) \mathbf{M u l t}_{\mathbf{s}}(s, t)\left(T_{\text {out }}^{*}(s, t)-T_{\text {int }}(l, t, k)\right)-\mathbf{R}(l, t, k)=0$

$v^{s \in S_{H O T}(l, t)\left|T_{\text {out }}^{*}(s, t) \leq T_{\text {int }}(l, t, k) \wedge T_{\text {in }}^{*}(s, t) \geq T_{\text {int }}(l, t, k)+\delta \quad s \in S_{C O L D}(l, t)\right| T_{\text {in }}^{*}(s, t) \leq T_{\text {int }}(l, t, k) \wedge T_{\text {out }}^{*}(s, t) \geq T_{\text {int }}(l, t, k)+\delta}$

$$
\begin{aligned}
& \mathbf{R}(l, t, k)=0 \\
& \mathbf{R B}_{\text {in }}(l, u, t)=r b_{\text {in }}(l, u, t) \mathbf{M u l t}_{\mathbf{t}}(u, t) \\
& \mathbf{R B}_{\text {out }}(l, u, t)=r b_{\text {out }}(l, u, t) \mathbf{M u l t}_{\mathbf{t}}(u, t) \\
& \sum_{u \in U_{L}(l)}\left(\mathbf{R B}_{\mathbf{i n}}(l, u, t)-\mathbf{R B}_{\text {out }}(l, u, t)\right)=0 \\
& \mathbf{R B}_{\text {out }}(l, u, t)-\sum_{(l, u, i, t) \in R B_{\text {links }}} \mathbf{R B}_{\text {flow }}(l, u, i, t)=\mathbf{R B}_{\text {in }}(l, u, t)-\sum_{(l, j, u, t) \in R B_{\text {links }}} \mathbf{R B}_{\text {flow }}(l, j, u, t)
\end{aligned}
$$

$\forall l \in L_{H C}, \forall t \in T, \forall k \in T I_{H C}(l, t)(9)$ $\forall l \in L_{H C}, \forall t \in T, \forall k \in\left\{T_{\min }(l, t), T_{\max }(l, t)\right\}(10)$

$$
\forall l \in L_{R B}, \forall u \in U_{L}(l), \forall t \in T(11)
$$$$
\forall l \in L_{R B}, \forall u \in U_{L}(l), \forall t \in T(12)
$$

$\forall l \in L_{R B}, \forall t \in T(13)$

$\operatorname{Mult}_{\mathbf{t}}(u, t)=\operatorname{Mult}_{\mathbf{t}}(u, t-1)+\left(\sum \mathbf{R B}_{\mathbf{i n}}(l, i, t) \varepsilon(i)-\sum \mathbf{R B}_{\text {out }}(l, j, t) / \varepsilon(j)\right) t_{o p}(t)$

$\forall l \in L_{R B}, \forall u \in U_{L}(l), \forall t \in T(14)$ $i \in S T O_{I N}(u), l \in L_{R B}\left|i \in U_{L}(l) \quad j \in S T O_{O U T}(u), l \in L_{R B}\right| j \in U_{L}(l)$

$\mathbf{R B}_{\text {flow }}(l, i, j, t)=0$

$\forall u \in S T O, \forall(l, i, j, t) \in R B_{\text {links }} \mid i \in S T O_{O U T}(u) \wedge j \in S T O_{I N}(u)(16)$ 
The objective is the minimization of the total annual cost of the energy system $\left(\mathbf{C}_{\text {tot }}\right)$, sum of the total annualized investment $\left(\mathbf{C}_{\text {inv }}\right)$ and of the yearly operating cost $\left(\mathbf{C}_{\mathbf{o p}}\right)$ of the units (Eq. 1).

\subsubsection{Unit sizing and costing}

The binary variable $\mathbf{U s e}_{\mathbf{t}}$ defines the use of a unit in a given period: if $\mathbf{U s e}_{\mathbf{t}}(u, t)=0$ the unit $u$ is not used in $t$, if $\mathbf{U s e}_{\mathbf{t}}(u, t)=1$ the unit is used. The binary parameter $u s e_{f}$ can be used to force the use of a unit in a given period (Eq. 2). The operation of a unit in a given period is defined by the variable Mult $_{\mathbf{t}}$. Units inputs and outputs are defined for the default size of the unit $\left(\right.$ Mult $\left._{\mathbf{t}}(u, t)=1\right)$ and are proportionally scaled based on the value of this variable. The parameters $f_{\min }$ and $f_{\max }$ define the lower and upper bound for the unit operation, respectively (Eq. 3). A unit is called "process" if use $f_{f}(u, t)=f_{\min }(u)=f_{\max }(u)=1$, otherwise it is called "utility".

The variables Use and Mult are linked to the investment decision. They represent the binary decision of purchasing the unit (Eq. 4) and the chosen size (Eq. 5) with respect to the default size, respectively.

The annualized investment cost of a unit is the sum of a fixed component $c_{i n v, f i x}$ related to the unit purchase, and a variable part $c_{i n v, v a r}$ associated to the chosen size (Eq. 6). The hourly operating cost of a unit is the sum of a fixed component $c_{o p, f i x}$ related to the use of the unit, and a variable part $c_{o p, v a r}$ associated to its operation. The hourly operating cost is multiplied by the period duration $t_{o p}(t)$ in order to calculate the total operating cost in period $t$ (Eq. 7 ).

\subsubsection{Heat Cascade}

Process integration enforces feasibility of heat exchange according to the second principle of thermodynamics. The following equations apply the classical heat cascading constraints following the process integration terminology [35].

Thermal streams have the same multiplication factor $\left(\mathbf{M u l t}_{\mathbf{s}}\right)$ of the unit they belong to (Eq. 8). They are described by their thermodynamic properties: corrected input/output temperature $\left(T_{\text {in }}^{*}, T_{\text {out }}^{*}\right)$, enthalpy $\left(H_{\text {in }}, H_{\text {out }}\right)$ and heat capacity flowrate $(c p)$. "Hot streams" are streams whose output enthalpy level is lower than the input one (heat sources), whereas "cold streams" have output enthalpy higher than input enthalpy (heat sinks). Streams belong to heat cascade layers. Each heat cascade layer is divided into temperature intervals defined by their lower temperature $T_{\text {int }}$. $\mathbf{R}$ is the amount of heat that is transferred from each temperature interval $k$ to the lower ones. It is equal to the heat cascaded from higher temperature intervals, resulting from the difference of heat provided by hot streams and heat needed by cold streams, to which the net heat available in $k$ (Eq. 9) is added.

$T_{\min }$ and $T_{\max }$ are the lowest and the highest temperature intervals of each heat cascade, respectively. Eq. 10 ensures that no heat is cascaded above $T_{\max }$ and below $T_{\min }$.

\subsubsection{Resource Balance}

Resource balance constraints ensure mass flow and power balance in the system.

$r b_{i n}$ is the default input value from a resource balance layer to a unit, whereas $r b_{\text {out }}$ is the default output from a unit to a resource balance layer. Each unit can have multiple inputs and outputs associated to different layers, but it can only have one input or output in the same layer. Inputs and outputs are scaled according to the operation of the unit in order to get the total input $\left(\mathbf{R B}_{\mathbf{i n}}\right.$, Eq. 11) and output (RB $\mathbf{R}_{\text {out }}$, Eq. 12) in each period. Eq. 13 enforces that each layer is balanced in each period, i.e. the sum of the outputs of all units in a given layer 
equals the sum of the inputs.

$\mathbf{R B}_{\text {flow }}$ defines connections between units belonging to the same resource balance layer. As units can be only "producers" or "consumers" with respect to a given layer, Eq. 14 ensures all the resource output of units is consumed by other units having the same resource as an input. This variable is needed, for example, if the exchange between specific units needs to be forbidden or restricted.

\subsubsection{Storage}

Storage units allow storage of resources across periods. Each storage unit can be thought of as a "tank". The level of the tank, i.e. the amount of energy or resource stored, is represented by the Mult th $_{\mathbf{t}}$ of this unit.

Each storage unit can have multiple inputs and outputs. In the optimization model each input or output corresponds to an "auxiliary" unit linked to the main storage. Input units close the balance of a given layer by storing a certain amount of the resource, increasing in this way the level of the main storage unit. On the other hand, output units can decrease the level of the storage by inputting the resource to the corresponding layer. Inputs and outputs to the storage can be associated with an efficiency $\varepsilon$. The level of the storage unit at the end of each period is equal to the level at the end of the previous period plus inputs minus outputs by the auxiliary units. This circular balance of the storage unit is ensured by Eq. 15. Eq. 16 enforces that no loop exists between output and input of a given storage unit.

\subsection{Performance Indicators}

Scenarios for biomass and geothermal technologies are evaluated based on economic and environmental Performance Indicators (PIs).

\subsubsection{Total annual cost}

The total annual cost of the energy system $\left(\mathbf{C}_{\text {tot }}\right.$, Eq. 1) is chosen as objective of the optimization model under the assumption that for a given pathway the sizing and operation of the energy system is determined by economic criteria.

The total annual cost results from the sum of the total annualized investment and maintenance cost of technologies, and the yearly operating cost of resources. For technologies and resources within the city boundaries (in terms of ownership) investment and Operation and Maintenance (O\&M) costs are accounted for, while a purchasing price is attributed to all imported resources. As an example, if natural gas is imported by a public service provider, only the cost paid at the import is accounted for. The profit made by the public service provider when selling the resource to private consumers is not accounted for in the total cost as it constitutes just a transfer of money within the system. This global approach to urban energy systems cost calculation has two main advantages: $i$ ) it avoids the need of assuming prices for produced fuels and exchanges within the urban system boundaries and $i i$ ) it allows the definition of only one indicator representing the global cost for the public.

Technologies investment costs are annualized based on their economic lifetime. In this framework, annualized investment cost of existing technologies is also accounted for. This is coherent with the fact that at the end of their lifetime these technologies need to be replaced. In this way, the cost of technologies is spread over their whole lifetime, whereas financial depreciation would only attribute this cost to their early years of operation, leaving an upfront investment cost to future generations. As further detailed in the $\mathrm{ESI}^{\ddagger}$ (section 3), a real discount rate is 
adopted and cost values are expressed in real 2015 currency in order to provide a common basis for comparison.

\subsubsection{LCA environmental impact indicators}

As shown in Figure 1 environmental impact indicators are calculated for each scenario after the optimization phase. Environmental impact is calculated following a LCA approach, i.e. taking into account emissions of technologies and resources "from cradle to grave". The reference database for impact assessment is ecoinvent [36]. Data used in the model are reported in the ESI $^{\ddagger}$. The impact categories of interest in this work are the GWP and the impact on Human Health $(\mathrm{HH})$, the latter included in order to account for the impact of biomass combustion. A different calculation approach is followed for these two categories.

For GWP calculation the "IPCC 2013 - GWP 100a" impact assessment method [37] is selected. The global annual emissions $G W P_{t o t}$, expressed in $\mathrm{ktCO}_{2}$-eq./year, are calculated with an approach symmetrical to the one used for the cost calculation (Eq. 17). They are defined as the sum of the emissions related to the construction $(C)$ and end-of-life $(E)$ of the energy conversion technologies $(T E C H)$, allocated to one year based on the technology lifetime $n$, and the emissions related to resources $(R E S)$. The latter are the emissions associated to fuels (from cradle to combustion) and imports of electricity. For resources, the construction phase corresponds to the extraction, processing and transportation whereas operation $(O)$ corresponds to fuel combustion. Operating emissions of technologies, mainly corresponding to auxiliary materials and maintenance, are accounted for only if they are non-negligible.

The conceptual separation between technologies and resources for GWP calculation allows the integration of biofuels without increasing the model complexity. As an example, Figure 2 shows that when SNG is produced it can be input in the natural gas layer, thus replacing its fossil equivalent. As a consequence, the total GWP emissions are reduced as the utilization of the fossil natural gas resource is lower. If emissions related to combustion were allocated to technologies, instead, unit models would need to be duplicated in order to account for the different emissions of fossil resources and their biogenic alternatives.

$$
G W P_{t o t}=\sum_{i \in T E C H}\left(\frac{G W P_{C, E}(i)}{n(i)}+G W P_{O}(i)\right)+\sum_{j \in R E S} G W P_{C, O}(j)
$$

On the other hand, HH emissions are technology-dependent. In this case, combustion emissions can not be allocated to the resources as the combustion processes vary based on the technology. Thus, for this category the operating emissions of technologies $\left(H H_{O}\right)$ include the resource combustion as well. Extraction, processing and transportation remain allocated to the resources (Eq. 18).

$$
H H_{t o t}=\sum_{i \in T E C H}\left(\frac{H H_{C, E}(i)}{n(i)}+H H_{O}(i)\right)+\sum_{j \in R E S} H H_{C}(j)
$$

Since there is no consensus on an impact assessment method for the human health indicator, two methods are chosen to address different aspects. The "impact 2002+" method [38], which includes an endpoint indicator for the human health, is widely used by the scientific community. It integrates a wide range of pollutants and health effects, such as respiratory effects, ionizing radiation or human toxicity. The Swiss Eco-factors 2013 [39], based on the method of the ecological scarcity ("ecoscarcity 2013"), provide a wide range of midpoint indicators related to specific environmental issues, and are based on the scientifically supported goals of the Swiss 
environmental policy. For this method, the category "main air pollutants and PM" has been chosen as another indicator representative of the human health. This indicator is more focused on air emissions, which are of particular concern in the case of wood combustion.

\subsection{Scenarios}

In the scenario definition phase, pathways for geothermal and biomass conversion technologies are enforced in order to explore the solution space.

\subsubsection{Individual scenarios}

Table 1 lists the 20 "individual" scenarios, i.e. scenarios in which geothermal and biomass options are separately assessed.

Table 1: List of individual scenarios

\begin{tabular}{lcc}
\hline$\#$ & Biomass & Geothermal \\
\hline 0 & - & - \\
1 & - & $3.8 \mathrm{~km}$ Direct use \\
2 & - & $3.8 \mathrm{~km}$ ORC \\
3 & - & $4.2 \mathrm{~km}$ Direct use \\
4 & - & $4.2 \mathrm{~km} \mathrm{ORC}$ \\
5 & - & $5 \mathrm{~km}$ Direct use \\
6 & - & $5 \mathrm{~km} \mathrm{ORC}$ \\
7 & - & $6 \mathrm{~km}$ Direct use \\
8 & - & $6 \mathrm{~km} \mathrm{ORC}$ \\
9 & - & $6 \mathrm{~km} \mathrm{Kalina}$ \\
10 & Wet wood boiler & - \\
11 & Dry wood boiler & - \\
12 & Wet wood CHP & - \\
13 & Dry wood CHP & - \\
14 & Pyrolysis boiler & - \\
15 & Pyrolysis CHP & - \\
16 & Wet Wood FT & - \\
17 & Dry Wood FT & - \\
18 & SNG in NG & - \\
19 & SNG CHP & - \\
20 & SNG Mobility & - \\
\hline & &
\end{tabular}

Scenario 0 is the base case reference scenario, with no wood use and no geothermal installation. Scenarios 1-9 evaluate different options for geothermal alone, i.e. no wood is used in the system. Each one of the options envisions the drilling of one well at different depths (aquifer at $3.8 \mathrm{~km}$, EGS at $4.2 \mathrm{~km}, 5 \mathrm{~km}$ and $6 \mathrm{~km}$ ). In all these scenarios the heat available from the geothermal resource can directly supply the DHN. In the "direct use" case this is the only possible use of geothermal heat. In the "ORC" and "Kalina" scenarios the respective electricity production or cogeneration cycles are also available. The cycles installed capacity is fixed based on the associated resource. As cycles are designed for this size [40], from the operation point of view they can either be used at their respective nominal capacity, or be left unused. The latter case would be motivated by a higher profitability of directly using the heat. 
In scenarios 10-20 the different wood conversion pathways are assessed in the absence of geothermal. The consumption of the total wet wood availability in the urban system $(100 \mathrm{kt} / \mathrm{y})$ is common to all scenarios. "Wet wood" (humidity $(\Phi)=50 \%$ ) can be processed in a dryer to obtain "dry wood" ( $\Phi=15 \%)$. In the cases of direct combustion of wood in boilers or cogeneration and of biochemical conversion with the FT process, wet wood and dry wood are considered as optional inputs. Under the assumption that the drying process is equivalent for all the modeled biofuel production processes, the comparison between wet and dry wood input in the FT case is considered representative for the SNG and pyrolysis cases. In the case of fuel production, all the different uses of the produced biofuels are accounted for. As an example, the default option for SNG is the replacement of fossil Natural Gas (NG) without impacting the technology mix (scenario 18). SNG could be also used in more efficient ways such as CHP (scenario 19) and in private mobility (scenario 20). As these technologies are not available in the reference scenario, this causes a change in the technology and fuel mix (e.g. SNG cars replacing diesel cars in mobility). Thus, these scenarios link the production of SNG to the deployment of CHP and cars using the biofuel as an input. Without a wider deployment of these technologies compared to the reference case, biofuels would simply replace their respective fossil equivalents.

Table 2: Avoided GWP emissions (resources only) associated to the different uses of $1 \mathrm{kWh}$ of electricity. Based on data as in the $\mathrm{ESI}^{\ddagger}$, unless otherwise specified.

\begin{tabular}{lc}
\hline Use type & $\begin{array}{c}\text { Avoided GWP100a }^{a} \\
{\left[\mathrm{kgCO}_{2} \text {-eq./ } / \mathrm{kWh}_{\mathrm{e}}\right]}\end{array}$ \\
\hline Substitution Swiss el. mix & 0.110 \\
Substitution UCTE el. mix & 0.482 \\
Heat pump $^{b}$ & 0.961 \\
Electric car $^{c}$ & 1.052 \\
\hline
\end{tabular}

\footnotetext{
${ }^{a}$ Only accounting for emissions related to resources. Emissions related to the production of the $\mathrm{kWh}$ of electricity not accounted for

${ }^{b}$ Assuming COP $=3.5$ and substitution of DHN NG boilers

${ }^{c}$ Assuming $0.199 \mathrm{kWh}_{\mathrm{e}} / \mathrm{km}[36]$ and substitution of diesel cars
}

Scenarios involving electricity production technologies are treated differently. The impact of an additional electricity production in the system, in fact, can vary significantly. As shown in Table 2, the impact on GHG is low when replacing a low-carbon electricity mix (such as the Swiss one), and high when replacing fossils with efficient electric technologies, such as replacing NG used in boilers with heat pumps or diesel used in cars with electric vehicles. The assumption is that electricity always replaces the current Union for the Co-ordination of Transmission of Electricity (UCTE) European electricity mix, which is chosen as a representative average between the possible available pathways. This mix has also a high $\mathrm{HH}$ impact. The choice is mainly motivated by the need of keeping the number of scenarios within a tractable number. The importance of linking the production of biofuels to a wider deployment of efficient technologies is discussed in [41].

\subsubsection{Combined scenarios}

The 9 individual scenarios for geothermal and 11 individual scenarios for biomass are systematically combined in order to investigate the interest of combining the two resources, with a particular focus on hybrid solutions. The 99 resulting scenarios are called "combined" scenarios. 


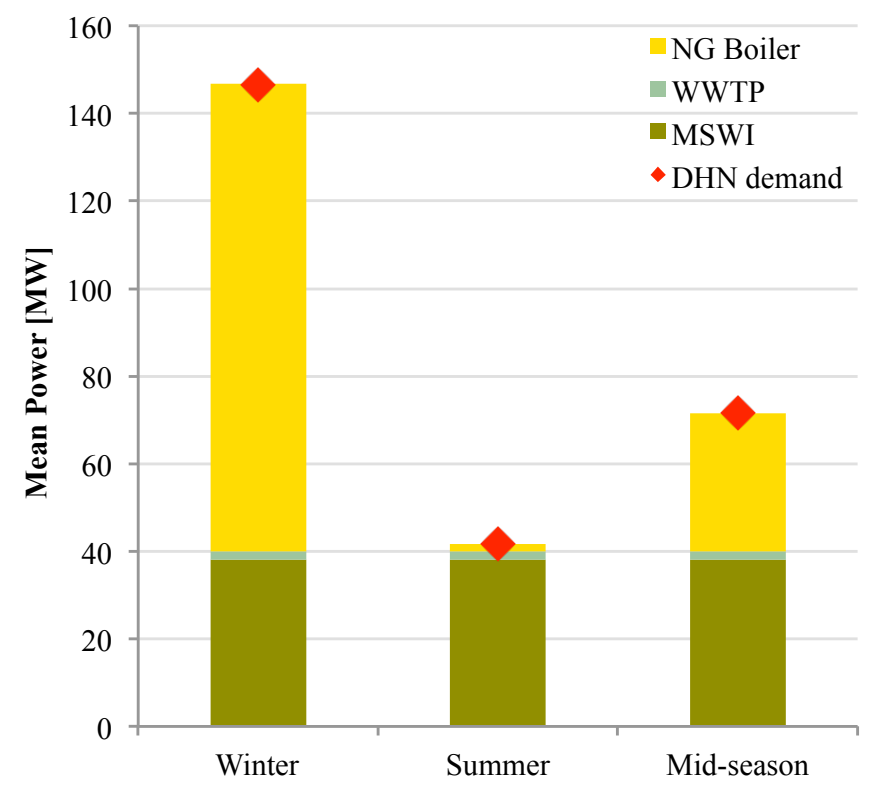

Figure 3: DHN Heat supply and demand in the reference scenario (scenario 0).

\section{Results}

\subsection{Individual scenarios: geothermal and biomass alone}

The 20 individual scenarios listed in Table 1 are the scenarios for which geothermal and biomass options are separately assessed. Performance indicators for the individual scenarios are reported in Figure 4: the subplots depict $H_{t o t}{ }^{2}(a)$ and $G W P_{t o t}(b)$ against the total annual cost $C_{t o t}$, respectively. The lower the value of the indicators, the better the scenario performance. Geothermal and biomass options are compared to the reference (scenario 0), which represents the default state of the urban energy system without any use of wood or geothermal. The reference scenario is characterized by a total annual cost of 544.6 MCHF, and annual emissions of $777.7 \mathrm{ktCO}_{2}$-eq. and $62.9 \mathrm{kpts}$, respectively. Resources are responsible for $31.9 \%$ of the total cost and for $92.0 \%$ of the global GHG emissions. In the reference scenario, the heat provided by the WWTP and MSWI can almost entirely satisfy the DHN heat demand during the summer period, with a very low share left to natural gas during this season (Figure 3).

\subsubsection{Geothermal options}

Scenarios 1-9 individually assess geothermal solutions at different depths, with the additional options of electricity production and cogeneration.

All EGS options (at $4.2 \mathrm{~km}, 5 \mathrm{~km}$ and $6 \mathrm{~km}$ ) allow a reduction of both the total cost and the environmental impact indicators compared to the reference scenario. For the total cost, this reduction is due to the fact that the savings generated by the reduction of natural gas imports for DHN heat production are greater than the annualized investment cost of the wells. The benefit is even higher for the environmental impact, as the emissions related to the drilling are substantially lower than the avoided emissions from fossil fuels combustion.

\footnotetext{
${ }^{2}$ The figure depicts only the "impact2002+" indicator. Results related to the "ecoscarcity 2013" indicator are reported in the $\mathrm{ESI}^{\ddagger}$.
} 


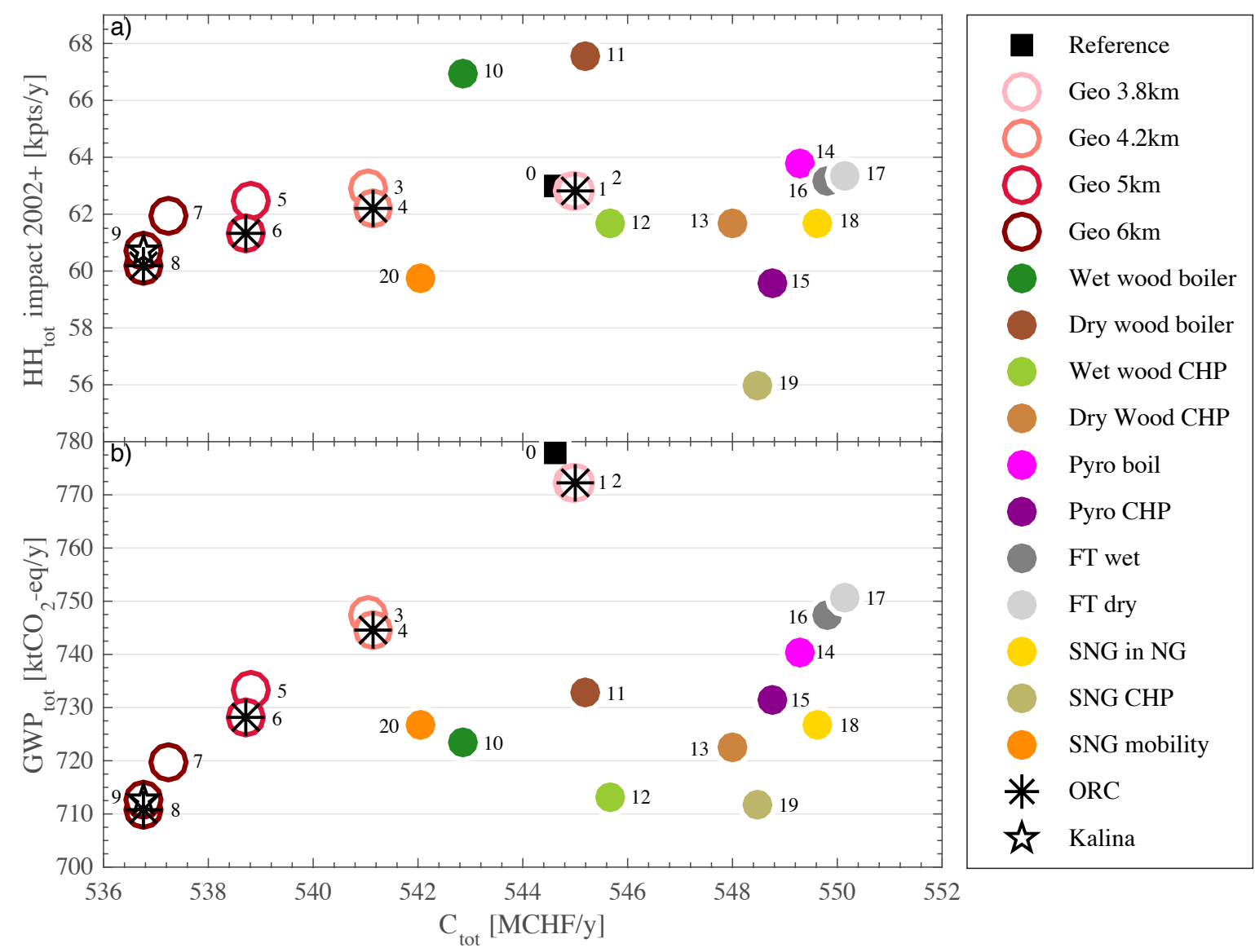

Figure 4: Results of the individual scenarios listed in Table 1: individual assessment of geothermal and biomass options.

When direct use of geothermal heat is the only available option, there is an excess of heat in summer as the DHN heat demand is already almost entirely satisfied by the MSWI and the WWTP. In the scenarios in which the installation of an ORC or Kalina cycle is forced in the system (scenarios 4, 6, 8, 9), this otherwise "waste" geothermal heat is converted to electricity. Results show that in all these scenarios the cycles are operated only during the summer period, while in the other seasons the "direct use" of geothermal heat is the optimal solution for the urban system. Thus, when there is a demand of heat in the system it is better to fully exploit the available geothermal heat to replace natural gas, instead of converting it to electricity at substantially lower efficiencies.

The benefits of EGS solutions increase with the depth of the installation, as the power-toinvestment cost ratio gets higher. The best option for geothermal is therefore the $6 \mathrm{~km}$ well with ORC (scenario 8), which allows yearly savings of $7.83 \mathrm{MCHF}, 67.0 \mathrm{ktCO}_{2}$-eq. and $2.75 \mathrm{kpts}$ compared to the reference scenario. The ORC is preferred to the Kalina cycle as cogeneration of heat and power is not an interesting option in summer. In winter the cogeneration option is not optimal due to the high temperature of the DHN, which strongly limits the share of useful heat that can be recovered from the cogeneration power plant.

On the other hand, the aquifer option at $3.8 \mathrm{~km}$ (scenario 1) is of little interest. Compared to the EGS alternatives, it features a comparable investment cost but with a much lower expected 
mass flow rate. This leads to a higher total cost of the system, as the annualized investment for the well is higher than the savings in natural gas imports. When the corresponding ORC is added in the system (scenario 2) it is never economical to use it.

\subsubsection{Biomass options}

Scenarios 10-20 individually assess different pathways for the conversion and use of the entire woody biomass potential (100 kt/y).

The scenarios with direct combustion of wood in boilers or cogeneration power plants (scenarios 10-13) generally perform better in terms of total cost. In scenario 10, involving the combustion of wet wood in a boiler, the total annual cost of the system is reduced $(-1.77 \mathrm{MCHF} / \mathrm{y})$. In fact, in this scenario the savings generated by the reduced natural gas imports are higher than the cost of wood harvesting and of wood boiler technologies. The best results in terms of GHG emissions reduction from direct wood combustion are obtained in the case of wet wood-based cogeneration. Compared to the boiler case, the lower savings associated with heat production are compensated by the avoided emissions of electricity imports. For both total costs and GWP, drying the wood externally prior to combustion is a suboptimal solution (scenarios 11 and 13). Dry wood combustion is advantageous compared to wet wood combustion as the efficiency is higher and there is less water in the wood to be evaporated. Nonetheless, as no excess heat is available in these scenarios, external wood drying requires an additional natural gas consumption in the system. This additional consumption is higher than the benefits generated by the combustion of dry wood. Thus, in absence of excess heat in the system, it is more efficient to directly burn wet wood instead of externally drying it prior to combustion. This is mainly due to the fact that the external drying evaporates the water contained in the wood at a lower efficiency $(52 \%)$ compared to the evaporation during the combustion process. The positive impacts on GHG emissions reduction, due to the lower NG consumption, are in trade-off with the negative impacts of wood combustion on human health. These negative impacts are mainly caused by the direct emissions of wood combustion. In the case of combustion in boilers, this leads to an overall increase of the human health impact compared to the reference scenario. This is more pronounced in the case of dry wood $(+4.58 \mathrm{kpts} / \mathrm{y}$ compared to the reference) due to the electricity and natural gas emissions associated to the external dryer. In the case of cogeneration, these emissions are compensated by the avoided electricity imports. The strong reduction is due to the high impact on human health of the UCTE electricity import mix.

Scenarios 14-20 assess the pathways for the chemical conversion of woody biomass to biofuels. Scenarios 18-20, which assess the conversion of wood to SNG, result in the highest reduction of GHG emissions, with global values which are comparable to the combustion pathways. This is due to the high efficiency of the SNG process $(74 \%$ fuel production with respect to wood input, on a wet basis). Scenario 18 is the default case, in which SNG replaces fossil NG. Scenario 19 (SNG CHP) offers the best results in terms of both GWP and HH, with a reduction of $66.0 \mathrm{ktCO}_{2}$-eq. and $6.96 \mathrm{kpts} / \mathrm{y}$, respectively. In terms of $\mathrm{GHG}$ emissions reduction, wet wood CHP is suboptimal compared to SNG CHP. The higher electrical efficiency of the latter, in fact, compensates the losses of the wood-to-SNG conversion. The use of SNG in mobility (scenario 20), linked to a corresponding deployment of SNG cars, offers the best performance in terms of cost. This is due to the high cost of diesel, which is partly substituted by SNG. This scenario has a similar performance in terms of GWP compared to scenario 18 due to the lower efficiency of SNG cars compared to diesel cars, which is in trade-off with the higher emissions of diesel compared to natural gas. The pyrolysis pathways (scenarios 14 and 15) present similar results but are limited with respect to GWP by a lower conversion efficiency $(66.6 \%$ fuel production with respect to wood input, on a wet basis), and with respect to $\mathrm{HH}$ by the direct 
emissions associated to the combustion of pyrolysis oil [42]. On the other hand, they present the advantage of lower initial investment costs. The production of Fischer-Tropsch fuels to substitute diesel mobility (scenarios 16-17) is the least interesting option, as it is characterized by a lower conversion efficiency ( $49.8 \%$ fuel production with respect to wet wood input, on a wet basis) and very high investment $\operatorname{costs}^{3}$, which strongly reduce the high savings in operating cost due to reduced diesel consumption. Scenario 17 is the scenario with the highest total cost $(+5.53 \mathrm{MCHF} / \mathrm{y})$.

Unlike the case of direct combustion, the comparison between internal and external drying of wood shows that the two options are basically equivalent for biofuel production processes. This is due to the fact that when the drying is performed within the process ("FT wet", scenario 16) using the available excess heat generated by the process itself, the efficiency is $62 \%$, which is comparable to the one of the external dryer. Hence, when the drying is performed externally ("FT dry", scenario 17) the additional natural gas consumption required by the drying process is almost equal to the reduction of natural gas imports caused by the supply of the excess process heat to the DHN. Thus, unlike for the case of direct combustion, in the case of biochemical conversion of woody biomass to biofuels and if no excess heat is available in the system, there is an equivalency between performing the drying externally or within the process. As mentioned in section 2.4, the results for the FT case can be extended to the pyrolysis and SNG processes as the drying process is the same for all these pathways.

\subsection{Combined scenarios: combination of biomass and geothermal options}

Biomass and geothermal options are systematically combined in order to evaluate possible synergies offered by the integration of the two resources. 99 additional scenarios are generated by combining the 9 individual scenarios for geothermal and the 11 individual scenarios for biomass listed in Table 1.

The performance of a given scenario with respect to the reference (scenario 0) and to each indicator is defined as in Eq. 19:

$\delta P I_{x}=P I_{x}-P I_{0}$

in which $P I_{x}$ is the value of a performance indicator $\left(C_{t o t}, G W P_{t o t}\right.$ or $\left.H H_{t o t}\right)$ for the scenario $x$. For the individual scenarios, $x$ is the scenario number as listed in Table 1 . For the scenarios in which geothermal and biomass options are combined, $x=(i, j)$, with $i$ being the scenario option for geothermal, and $j$ the scenario option for biomass, again numbered as in Table 1 . As an example, scenario $(1,10)$ is the combination of the $3.8 \mathrm{~km}$ aquifer for geothermal (scenario 1 ) with the wet wood boiler for biomass (scenario 10). The lower the value of $\delta P I_{x}$, the better the performance of scenario $x$ compared to the reference case (scenario 0 ).

In order to evaluate the interest of the combined scenarios, a new indicator is defined as in Eq. 20:

$\Delta P I_{(i, j)}=\delta P I_{(i, j)}-\left(\delta P I_{i}+\delta P I_{j}\right)$

$\Delta P I_{(i, j)}$ compares the performance of a given combined scenario $\left(\delta P I_{(\mathrm{i}, \mathrm{j})}\right)$ to the sum of the performance of the two corresponding individual scenarios $\left(\delta P I_{\mathrm{i}}+\delta P I_{\mathrm{j}}\right)$. If $\Delta P I_{(i, j)}=0$, the combination of the options $i$ and $j$ is equal to the sum of the benefits provided by scenarios

\footnotetext{
${ }^{3}$ The FT model is based on [43], in which it is optimized for a bigger size compared to the one considered in this work.
} 
$i$ and $j$ alone. If $\Delta P I_{(i, j)}<0$, the combination generates a "positive synergy", i.e. combining options $i$ and $j$ generates more savings than the sum of the savings provided by scenarios $i$ and $j$ alone. If $\Delta P I_{(i, j)}>0$ instead, the combination generates a "negative synergy", i.e. combining options $i$ and $j$ generates less savings than the sum of the savings provided by scenarios $i$ and $j$ alone.

Figure 5 plots the values of $\Delta C_{t o t}$ and $\Delta G W P_{t o t}$ for the 99 combined scenarios. The use of symbols to refer to the scenarios in this figure is consistent with the convention used in Figure 4. The dotted red lines highlight the points for which $\Delta P I_{(i, j)}=0$. Out of the 99 scenarios, 37 lie at the intersection of these red lines. For these scenarios, both in terms of cost and of GWP, the combination between geothermal and biomass options has no advantage or disadvantage compared to the sum of the same options alone. Thus, these scenarios are not further discussed here as their performance is the sum of the benefits of the corresponding individual scenarios highlighted in Figure 4.

The next sections describe in detail the scenarios presenting positive and negative synergies when integrating geothermal and biomass.

\subsubsection{Combined scenarios: negative synergies}

Scenarios presenting negative synergies are shown in the upper right quadrant of Figure 5, delimited by the dotted red lines. Out of the 35 scenarios showing a non-zero variation in terms of total cost, 21 show also a non-zero variation in terms of GWP (some points are exactly overlapping in the graph).

For the combined scenarios having a negative effect only on the total cost indicator $\left(\Delta G W P_{t o t}=\right.$ 0 ), the difference derives by the sizing of the biomass energy conversion technologies. Among these scenarios, the ones combining wet wood based cogeneration with the EGS geothermal options show the worst performance in this regard. The reason is that in the individual scenario for wet-wood based cogeneration (scenario 12) the available wood is burned partly in winter and partly during the mid-season. When the EGS resources are added, it is economically optimal to burn the entire wood during winter, and therefore a bigger CHP unit is needed. The same applies to the scenarios combining pyrolysis CHP with the EGS options at $5 \mathrm{~km}$ and $6 \mathrm{~km}$. In this case, this happens only with the geothermal options at higher depth because these two options can satisfy (fully in the case of the $6 \mathrm{~km}$ ) the heat requirements of the DHN during the mid-season period.

The 21 scenarios showing a negative synergy also for the GWP indicator are those that include SNG production, with the exclusion of the ones coupled to $4.2 \mathrm{~km}$ and $5 \mathrm{~km}$ ORC options. For all these scenarios, the negative synergy for the GWP indicator is motivated by the slightly increased consumption of fossil natural gas in the system. In fact, in the individual scenarios involving SNG production (scenarios 18-20) the extra heat available in the SNG process is sufficient to replace the natural gas needed during the summer period to satisfy the small DHN heat requirement not provided by the MSWI and the WWTP. As this advantage of the SNG process is already included in the individual scenarios, the combined scenarios with the EGS options cannot benefit from this reduction. This additional natural gas consumption could be avoided by not operating the SNG process during the summer period, though this would lead to a substantial increase in the investment costs.

In general, the negative synergies associated to the integration are not significant and motivated by the choice of the total cost as objective of the MILP problem. 


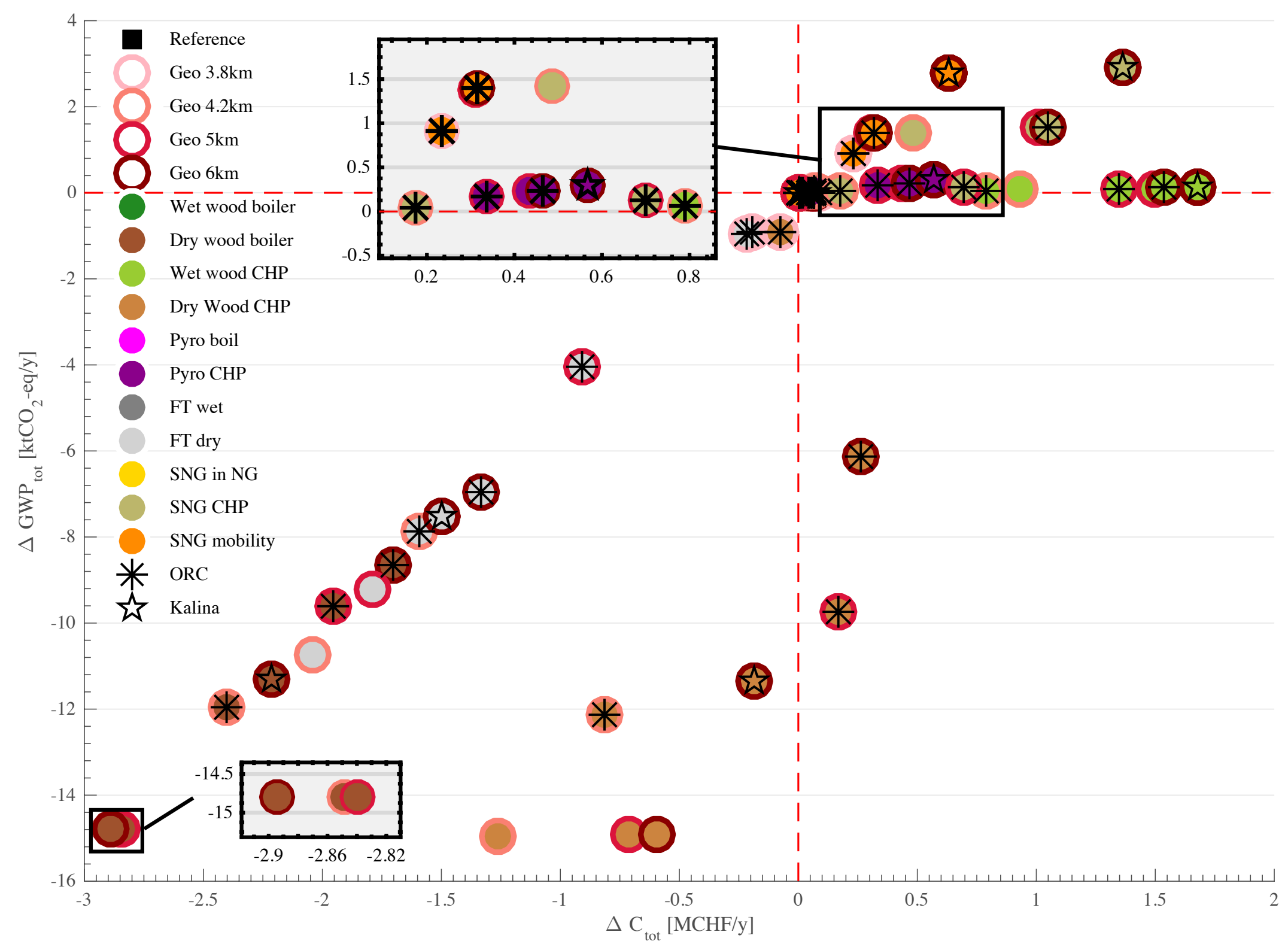

Figure 5: $\Delta C_{t o t}$ and $\Delta G W P_{t o t}$ for the geothermal-biomass combined scenarios. 


\subsubsection{Combined scenarios: positive synergies}

Scenarios presenting positive synergies with respect to GWP are shown in the lower part of Figure 5, delimited by the horizontal dotted red line. This group of 27 scenarios consists of the combination of the three scenarios with external drying of wood (scenarios 11, 13 and 17) with all the 9 options for geothermal. Out of these 27 scenarios, 25 show also a positive synergy in terms of total cost (lower left quadrant of the figure). As discussed in section 3.1.2 in the individual scenarios there is no interest for external drying of wood, especially in the case of wood combustion, where the suboptimality of external drying is greater. This is due to the fact that in the absence of excess heat in the system, external drying requires an additional consumption of fossil natural gas. As the MSWI and the WWTP supply the quasi-entirety of the heat needed in summer, when geothermal options are added in the combined scenarios, geothermal heat in summer represents instead an excess in the system. The positive synergy of these combined scenarios derives from the integration of excess geothermal heat in the biomass drying process, which leads to a global increase in the conversion efficiency.

The six combined scenarios integrating the $3.8 \mathrm{~km}$ aquifer resources are of least interest. This is due to the low thermal output of the aquifer well. On the other hand, the integration of the three EGS direct use options for dry wood combustion (boilers and CHP) shows the highest improvement compared to the individual scenarios in terms of GHG emissions. This reduction is motivated by the substitution of fossil natural gas with geothermal heat for wood drying. In terms of total cost, the savings in natural gas imports are greater than the increased investment costs for wood boilers, CHP and storage units. In the case of cogeneration, as highlighted in the previous paragraph, the need of entirely burning the wood in winter causes higher investment costs for the cogeneration unit.

In the case of direct use of EGS integrated with combustion of dry wood, the maximum synergies are already obtained with the resource at $4.2 \mathrm{~km}$ depth. This is due to the fact that the excess heat in summer available from the $4.2 \mathrm{~km}$ well summed to the heat production from the MSWI is enough to dry the entire wet wood available, while at the same time satisfying the heat demand of the DHN. Thus, the $5 \mathrm{~km}$ and $6 \mathrm{~km}$ EGS options do not offer additional advantages in terms of synergy between the two resources.

The "FT dry" process has an excess heat available, corresponding to the amount of heat used in the "FT wet" option for wood drying. This excess heat is used for DHN heat supply. When combined with the direct use EGS options, differently from the case with dry wood combustion, the best performance is achieved with the $4.2 \mathrm{~km}$ EGS option. The reason is that the options at $5 \mathrm{~km}$ and $6 \mathrm{~km}$ can satisfy (fully in the $6 \mathrm{~km}$ case) the DHN heat requirements in the mid-season, so in this season the extra heat available from the "FT dry" process is in excess. In the case of integration with the $4.2 \mathrm{~km}$ well, this excess heat is also fully exploited during that period of the year, leading to better system integration and lower fossil natural gas consumption.

In the "direct use" individual scenarios the excess geothermal heat is almost entirely wasted. In the ORC and Kalina individual scenarios the cycles already partially exploit the excess geothermal heat in summer by converting it to electricity. This explains why in this figure the direct use EGS options show higher reductions than the options with ORC or Kalina cycles at $4.2 \mathrm{~km}$ and $5 \mathrm{~km}$. In other words, a more efficient use of the excess geothermal heat in the individual scenarios reduces the benefits brought by the integration with the biomass drying processes. This is highlighted in Figure 5 for the points in which wood dry options are integrated with ORCs at different depths: the positive synergy is lower for the $5 \mathrm{~km}$ compared to the $4.2 \mathrm{~km}$ EGS, as the $5 \mathrm{~km}$ option features a higher production of electricity in the corresponding individual scenario. In these combined scenarios, the cycles are not operated during summer as the heat is used for wood drying. An exception is represented by the combination between the dry wood 
conversion processes and the EGS options at $6 \mathrm{~km}$ with ORCs. In these combined scenarios, it is economically optimal to operate the cycles during the summer period due to the higher electrical efficiency of the supercritical cycle. This means that the wood is also partly dried during winter, causing a higher fossil natural gas consumption in the system. This increase is more pronounced in the case of dry wood combustion compared to the FT due to the lower global efficiency of the external wood drying.

In general, the integration between biomass and geothermal options offers opportunities for strong positive synergies, identifying the interest of hybrid solutions in which the excess geothermal heat in summer is integrated in the wood drying process.

The $\triangle P I_{(i, j)}$ indicator, adopted in Figure 5, is a relative indicator, ranking geothermalbiomass combinations relatively to the corresponding individual scenarios. A good performance of a combined scenario (low value of $\Delta P I_{(i, j)}$ ) can also be due to a suboptimal condition in the corresponding individual scenarios, and vice-versa. In other words, an efficient (inefficient) use of a resource in the individual scenarios can decrease (increase) the positive synergy of a combined scenario. An example is the highlighted negative synergy case of the SNG process, which is due to the fact that the corresponding individual scenarios are already benefiting from a reduced fossil natural gas consumption in periods of low DHN heat demand.

\subsection{Evaluation of hybrid processes}

Thus, to complete the analysis performed in the previous section, the 27 hybrid solutions need to be compared in absolute values. To do this, a new indicator is defined, comparing the corresponding geothermal-biomass combinations with and without external drying (Eq. 21):

$\Delta_{\text {Hybrid }} P I_{(i, k)}=P I_{(i, j)}-P I_{(i, j-1)}$

in which $k$ is a biomass conversion process for which the external drying option is defined (FT, wood boiler and wood CHP), $j$ is the corresponding individual scenario with external drying ( $j=11,13$ and 17 , respectively) and $j-1$ is the corresponding individual scenario fuelled with wet wood. The indicator is calculated for all geothermal options $i \in[0 ; 9]$. Individual scenarios are numbered as in Table 1. $\Delta_{\text {Hybrid }} P I$ is the difference between the biomass conversion process having dry wood as an input (external drying) and the same process fuelled with wet wood, with respect to a given performance indicator. As an example, $\Delta_{\text {Hybrid }} G W P_{\text {tot, }(1, F T)}$ is the difference between the "FT dry" $(j=17)$ and the "FT wet" processes $(j-1=16)$, both integrated with the $3.8 \mathrm{~km}$ aquifer for geothermal $(i=1)$, with respect to the $G W P_{\text {tot }}$ performance indicator.

Results of the analysis are depicted in Figure 6 , plotting the $\Delta_{\text {Hybrid }}$ indicator for the total cost and the GHG emissions. The dotted red lines indicate the points for which $\Delta_{\text {Hybrid }} P I_{(i, k)}=0$. For points lying on these lines the wet process is equivalent to the process with external drying, i.e. no advantage or disadvantage is associated with the external drying process. If $\Delta_{H y b r i d} P I_{(i, k)}>0$ then the wet process performs better than the dry option. In these cases, there is no interest for external drying. If $\Delta_{H y b r i d} P I_{(i, k)}<0$ then the option with external drying has a better performance than the wet wood fuelled option. Thus, the lower left quadrant of the graph highlights and ranks the hybrid solutions of interest. The lower the $\Delta_{H y b r i d} P I_{(i, k)}$, the greater the interest of the geothermal-biomass hybrid system.

As a reference, the graph shows as well the $\Delta_{H y b r i d}$ indicator for the individual scenarios, in which no geothermal option is activated. As expected, the individual scenarios are in the upper right quadrant of the figure. As discussed in section 3.1.2, external wood drying is not an 


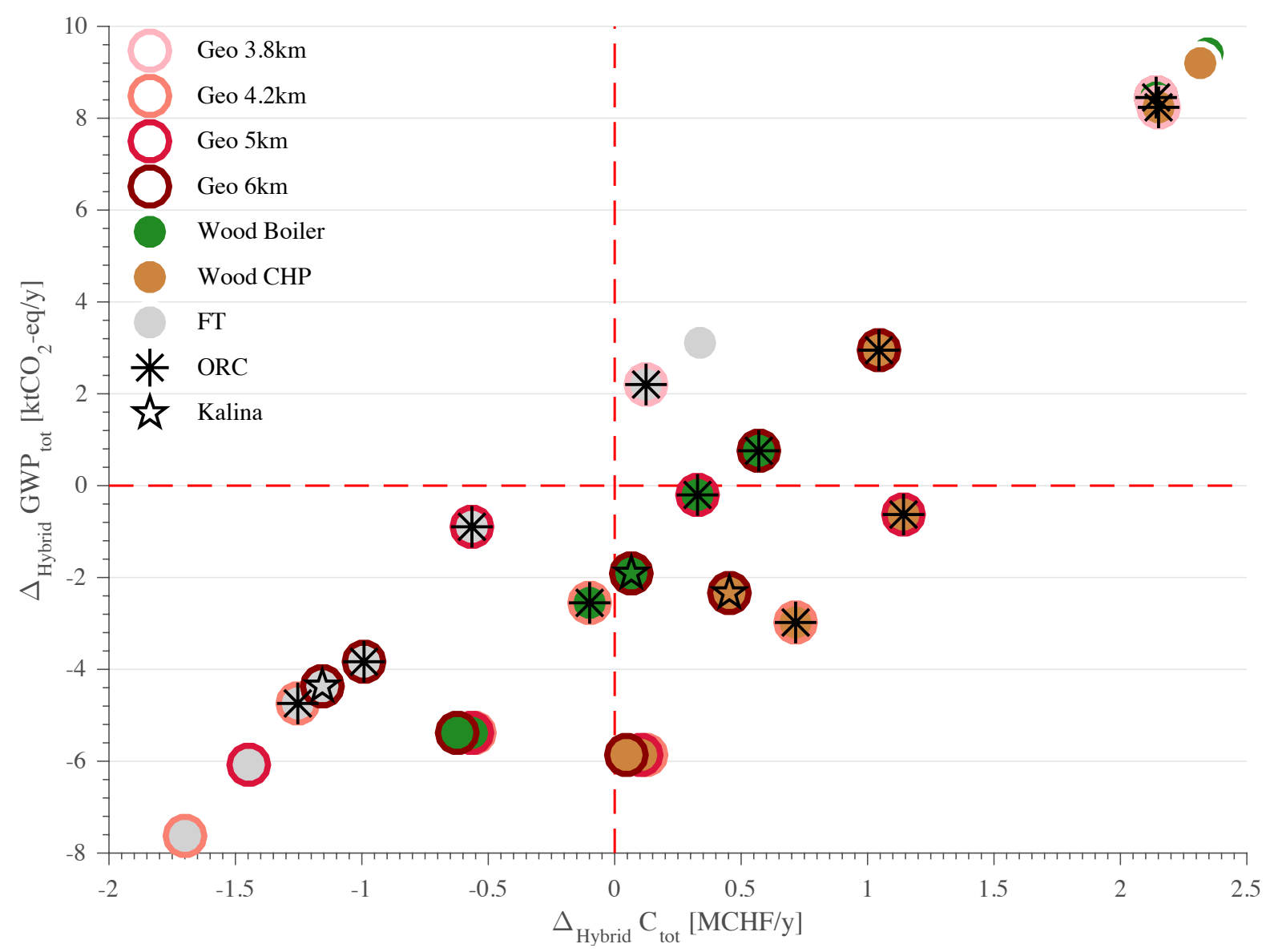

Figure 6: $\Delta_{H y b r i d} C_{t o t}$ and $\Delta_{H y b r i d} G W P_{t o t}$ for the hybrid biomass-geothermal processes.

interesting option for the individual scenarios, as it leads to an overall increase of fossil natural gas consumption in the system. For these options, the wet wood fuelled process is more efficient than the dry wood process with external drying. The reason lies in the lower efficiency of external drying in evaporating the water contained in the wood. The suboptimality is greater in the case of processes with wood combustion, whereas for the biofuel production processes the difference in efficiency is lower. This explains the lower suboptimality of the FT process highlighted in the graph.

Scenarios with $\Delta_{\text {Hybrid }} P I_{(i, k)}>0$, in the upper right quadrant of the figure, feature an overall increase of NG consumption in the system in the "dry" case compared to the "wet" option. All the biomass processes combined with the $3.8 \mathrm{~km}$ aquifer do not show an interest for external drying. In fact, the heat potential of the aquifer can supply only a small part of the heat needed to dry the entire wood available. Thus, in these cases the savings of natural gas due to the integration with geothermal heat in the drying process are lower than the additional natural gas consumption needed to dry the rest of the wood. The same applies to the combustion of dry wood coupled with the EGS $6 \mathrm{~km}$ ORC option. As previously discussed, operating the ORC cycles during summer has for consequence a higher NG consumption for wood drying in the other seasons.

Concerning the scenarios with negative $\Delta_{\text {Hybrid }}$ values, the best scenario for both indicator is the combination of the "FT dry" process with the EGS at $4.2 \mathrm{~km}$. As previously discussed, 
this is due to the fact that in this scenario the best balance in the system is achieved, allowing to fully exploit the geothermal heat in summer and the additional heat available from the FT process in the other seasons. Reaching higher depths for the geothermal wells would lead to lower benefits in terms of integration with the biomass chemical conversion processes, as there would be an excess of heat in the mid-season.

The comparison in absolute values of the hybrid geothermal-biomass options allows the identification of an optimal solution, maximizing the integration between the two resources. Due to the equivalence of the drying process, the results obtained for the FT can be extended to the pyrolysis and SNG processes.

The chemical biomass conversion pathways benefit more from the hybridization than the wood combustion processes. This can be considered a general result as it depends on the efficiencies of the involved processes. On the other hand, the identification of the $4.2 \mathrm{~km}$ EGS option as the optimal one for the hybrid system is determined by the integration in the urban system. The seasonal variations of the demand in energy services and the constraints given by the presence of other energy conversion technologies strongly impact the evaluation of the different options.

\section{Conclusions}

A methodology for the integration of deep geothermal energy and woody biomass resources in urban energy systems is developed and demonstrated by an application case study.

A multiperiod MILP formulation for urban energy system modeling is proposed. The formulation includes process integration in order to account for potential hybrid solutions leading to positive synergies between the considered resources. The scenario-based methodology offers a systematic evaluation of all the available options for deep geothermal and woody biomass. Performance indicators are the total annual cost of the energy system, objective of the MILP, and environmental impact indicators (GWP and human health).

The methodology is applied to the urban system of Lausanne, Switzerland. First, geothermal and biomass options are separately evaluated. For geothermal, aquifer and EGS options are considered. Compared to the reference scenario, which features no wood use and no geothermal installation, all the EGS options allow a reduction of both the total cost and the environmental impact indicators. The direct use of geothermal heat in the district heating network of the city is the best option for geothermal energy. In periods of low heating demand, the MSWI and WWTP can almost entirely supply the district heating network. Thus, geothermal heat is in excess during these periods. The conversion of this excess heat to electricity with ORC allows to further improve the environmental performance indicators. The option of cogeneration is limited by the high temperature of the DHN.

For woody biomass, the best results are offered by the conversion of wood to SNG. The substitution of diesel cars with SNG cars offers the best performance in terms of cost, whereas GHG emissions and HH impacts are minimized by the combustion of SNG in CHP units. Pyrolysis scenarios are limited by a lower conversion efficiency and by the impact on human health associated to BioOil combustion. Wood combustion pathways show good performances in terms of GHG emissions and have the advantage of lower investment costs. The option of direct combustion of wood is penalized by a negative impact on human health.

In the individual scenarios for woody biomass, wet $(\Phi=50 \%)$ and dry $(\Phi=15 \%)$ wood are evaluated as optional inputs. When no excess heat is available in the system, there is no interest for external wood drying, as the heat requirement of the dryer leads to an overall increase of fossil natural gas consumption in the system. On the other hand, when the combination of geothermal and biomass options is evaluated, the excess geothermal heat in summer can be integrated in the wood drying process. These hybrid systems can achieve higher savings in 
terms of total annual costs and GHG emissions than the corresponding geothermal and biomass options alone. The processes involving the chemical conversion of woody biomass to biofuels benefit the most from the integration with geothermal energy, in particular with the EGS resource at $4.2 \mathrm{~km}$. The identification of hybrid geothermal-biomass processes for wood drying emerges as an efficient way of storing excess heat in summer in urban energy systems, leading to an increase in the global efficiency.

In a stand-alone comparison of the technologies, it is often assumed that a demand exists for the produced energy services. This limit is overcome by contextualizing the comparison within urban energy systems. The application to a case study shows that taking into account the seasonal variations of the demand in energy services and the constraints given by the presence other energy conversion technologies strongly impacts the results.

The long time horizon inherent to strategic energy planning requires uncertainty to be accounted for, in particular when dealing with new technologies such as EGS. Thus, uncertainty classification and optimization under uncertainty will be included in future work in order to evaluate the impact of uncertainty on the results.

Other goals are an increase of the time resolution and the inclusion of more energy conversion technologies (such as heat pumps and solar) in the model. The case study has been limited to technologies and pathways which are possible to be considered by the City of Lausanne in the future. The inclusion of more efficient electric technologies (such as heat pumps and electric vehicles) is expected to increase the advantages linked to the production of electricity and biofuels such as SNG, which can be used in efficient energy conversion pathways. 


\section{Acronyms and abbreviations}

$\begin{array}{ll}\Phi & \text { Humidity } \\ C & \text { Construction } \\ E & \text { End-of-life } \\ O & \text { Operation } \\ R E S & \text { Resources } \\ T E C H & \text { Technologies } \\ \text { CHP } & \text { Cogeneration of Heat and Power } \\ \text { DHN } & \text { District Heating Network } \\ \text { EGS } & \text { Enhanced Geothermal System } \\ \text { FT } & \text { Fischer-Tropsch } \\ \text { GHG } & \text { Greenhouse gas } \\ \text { GWP } & \text { Global Warming Potential } \\ \text { HH } & \text { Human Health } \\ \text { LCA } & \text { Life Cycle Assessment } \\ \text { MILP } & \text { Mixed-Integer Linear Programming } \\ \text { MSWI } & \text { Municipal Solid Waste Incinerator } \\ \text { NG } & \text { Natural Gas } \\ \text { O\&M } & \text { Operation and Maintenance } \\ \text { ORC } & \text { Organic Rankine Cycle } \\ \text { PI } & \text { Performance Indicator } \\ \text { SNG } & \text { Synthetic Natural Gas } \\ \text { UCTE } & \text { Union for the Co-ordination of Transmission of Electricity } \\ \text { WWTP } & \text { Waste Water Treatment Plant }\end{array}$

\section{Acknowledgements}

This work was performed in the framework of the GEOTHERM2 project, co-founded by the Competence Center Energy and Mobility of the ETH Domain (CCEM) and the Competence Center Environment and Sustainability (CCES). The research work for this paper was in part financially supported by the Swiss Competence Center for Energy Research BIOSWEET Biomass for Swiss Energy Future.

The authors would like to thank the SiL (Services Industriels de Lausanne) and the City of Lausanne for the support and the active collaboration in this research work. Thank you also to the colleagues who have proofread the work and offered precious insights: Jefferson W. Tester (Cornell University), Stéphane Bungener and Sophia Wallerand (EPFL). Thank you to Fréderic Amblard (EPFL) for the contribution to the model development.

\section{References}

[1] IEA. Energy Technology Perspectives 2014. Technical report, IEA - International Energy Agency, 2014.

[2] IEA. Key World Energy Statistics 2014. Technical report, IEA - International Energy Agency, 2014.

[3] IPCC. Special Report on Renewable Energy Sources and Climate Change Mitigation. Cambridge University Press, United Kingdom and New York, NY, USA, 2011. 
[4] M. Fatih Demirbas, Mustafa Balat, and Havva Balat. Potential contribution of biomass to the sustainable energy development. Energy Conversion and Management, 50(7):17461760, July 2009.

[5] IEA - International Energy Agency. Technology Roadmap - Geothermal Heat and Power. Technical report, June 2011.

[6] United Nations. World Urbanization Prospects - The 2014 Revision. Technical report, United Nations, 2014.

[7] IEA. World Energy Outlook 2008. Technical report, IEA - International Energy Agency, 2008.

[8] Ingrid Stober, Thomas Fritzer, Karsten Obst, and Rüdiger Schulz. Deep Geothermal Energy - Application possibilities in Germany. Technical report, German Federal Ministry for Economic Affairs and Energy (BMWi), 2014.

[9] Mark Z. Jacobson. Review of solutions to global warming, air pollution, and energy security. Energy \& Environmental Science, 2(2):148-173, January 2009.

[10] Don B. Fox, Daniel Sutter, and Jefferson W. Tester. The thermal spectrum of lowtemperature energy use in the United States. Energy \& Environmental Science, 4(10):3731, 2011.

[11] Urban Persson and Sven Werner. Heat distribution and the future competitiveness of district heating. Applied Energy, 88(3):568-576, March 2011.

[12] Poul Erik Grohnheit and Bent Ole Gram Mortensen. Competition in the market for space heating. District heating as the infrastructure for competition among fuels and technologies. Energy Policy, 31(9):817-826, July 2003.

[13] James Keirstead, Mark Jennings, and Aruna Sivakumar. A review of urban energy system models: Approaches, challenges and opportunities. Renewable and Sustainable Energy Reviews, 16(6):3847-3866, August 2012.

[14] Jiyong Kim, S. Murat Sen, and Christos T. Maravelias. An optimization-based assessment framework for biomass-to-fuel conversion strategies. Energy \& Environmental Science, 6(4):1093-1104, March 2013.

[15] Léda Gerber, Samira Fazlollahi, and François Maréchal. A systematic methodology for the environomic design and synthesis of energy systems combining process integration, Life Cycle Assessment and industrial ecology. Computers \& Chemical Engineering, 59:2-16, December 2013.

[16] Poul Alberg Østergaard, Brian Vad Mathiesen, Bernd Möller, and Henrik Lund. A renewable energy scenario for Aalborg Municipality based on low-temperature geothermal heat, wind power and biomass. Energy, 35(12):4892-4901, December 2010.

[17] H Lund and E Münster. Modelling of energy systems with a high percentage of CHP and wind power. Renewable Energy, 28(14):2179-2193, November 2003.

[18] Curtis R. Sommer, Michael J. Kuby, and Gordon Bloomquist. The spatial economics of geothermal district energy in a small, low-density town: a case study of Mammoth Lakes, California. Geothermics, 32(1):3-19, February 2003. 
[19] Ioannis Vallios, Theocharis Tsoutsos, and George Papadakis. Design of biomass district heating systems. Biomass and Bioenergy, 33(4):659-678, April 2009.

[20] Antonio M Pantaleo, Sara Giarola, Ausilio Bauen, and Nilay Shah. Integration of biomass into urban energy systems for heat and power. Part I: An $\{$ MILP $\}$ based spatial optimization methodology. Energy Conversion and Management, 83:347-361, 2014.

[21] E. Alakangas, G. Borgström, T. Felber, G. Göttlicher, P. Grammelis, J. Habart, W. Haslinger, R. Jansen, M. Martin, K. Mutka, and A. Weissinger. Strategic Research Priorities for Biomass Technology. Technical report, European Technology Platform on Renewable Heating and Cooling, 2012.

[22] John W Lund, Karl Gawell, Tonya L Boyd, and Dan Jennejohn. The United States of America Country Update 2010. In 35th Workshop on Geothermal Reservoir Engineering Proceedings, pages 25-29, Stanford University, Stanford, CA (USA), 2010.

[23] Aleksandra Borsukiewicz-Gozdur. Dual-fluid-hybrid power plant co-powered by lowtemperature geothermal water. Geothermics, 39(2):170-176, June 2010.

[24] Ian Thain and Ronald DiPippo. Hybrid Geothermal-Biomass Power Plants: Applications, Designs and Performance Analysis. In World Geothermal Congress 2015 Proceedings, Melbourne (Australia), 2015.

[25] Birol Kilkis. A lignite-geothermal hybrid power and hydrogen production plant for green cities and sustainable buildings. International Journal of Energy Research, 35(2):138-145, February 2011.

[26] Maciej Z Lukawski, Konstantinos Vilaetis, Lizeta Gkogka, Koenraad F Beckers, Brian J Anderson, and Jefferson W Tester. A Proposed Hybrid Geothermal-Natural Gas-Biomass Energy System for Cornell University. Technical and Economic Assessment of Retrofitting a Low-Temperature Geothermal District Heating System and Heat Cascading Solutions. In 38th Workshop on Geothermal Reservoir Engineering Proceedings, Stanford University, Stanford, CA (USA), 2013.

[27] Koenraad F Beckers, Maciej Z. Lukawski, Gloria A. Aguirre, Sean D. Hillson, and Jefferson W. Tester. Hybrid Low-Grade Geothermal-Biomass Systems for Direct-Use and Co-Generation: from Campus Demonstration to Nationwide Energy Player. In 40th Workshop on Geothermal Reservoir Engineering Proceedings, Stanford University, Stanford, CA (USA), 2015.

[28] Monu Malik, Ibrahim Dincer, and Marc A. Rosen. Development and analysis of a new renewable energy-based multi-generation system. Energy, 79:90-99, January 2015.

[29] Frédéric Louis-Pierre Raphaël Marie Amblard. Geothermal energy integration in urban systems. The case study of the city of Lausanne. Master's thesis, EPFL, Lausanne, Switzerland, 2015.

[30] Stefano Moret, Léda Gerber, Frédéric Amblard, Emanuela Peduzzi, and François Maréchal. Geothermal Energy and Biomass Integration in Urban Systems: a Case Study. In 40th Workshop on Geothermal Reservoir Engineering Proceedings, Stanford University, Stanford, California, USA, 2015. 
[31] François Maréchal and Boris Kalitventzeff. Process integration: Selection of the optimal utility system. Computers \& Chemical Engineering, 22, Supplement 1:S149-S156, March 1998.

[32] Raffaele Bolliger. Méthodologie de la synthèse des systèmes énergétiques industriels. Doctoral Thesis, EPFL, Lausanne, 2010.

[33] Robert Fourer, David Gay, and Brian Kernighan. AMPL: A Modeling Language for Mathematical Programming. Duxbury Press, November 2002.

[34] Stéphane Laurent Bungener. Multi-Objective Optimisation of District Energy Systems. Master's thesis, École Polytechnique Fédérale de Lausanne, 2012.

[35] Ian C. Kemp. Pinch Analysis and Process Integration: A User Guide on Process Integration for the Efficient Use of Energy. Butterworth-Heinemann, April 2011.

[36] B.P. Weidema, C. Bauer, R. Hischier, C. Mutel, T. Nemecek, J. Reinhard, C.O. Vadenbo, and G. Wernet. The ecoinvent database: Overview and methodology, Data quality guideline for the ecoinvent database version 3. 2013.

[37] IPCC. Climate Change 2013: The Physical Science Basis. Contribution of Working Group I to the Fifth Assessment Report of the Intergovernmental Panel on Climate Change. Cambridge University Press, Cambridge, UK, 2013.

[38] Olivier Jolliet, Manuele Margni, Raphaël Charles, Sébastien Humbert, Jérôme Payet, Gerald Rebitzer, and Ralph Rosenbaum. IMPACT 2002+: A new life cycle impact assessment methodology. The International Journal of Life Cycle Assessment, 8(6):324-330, November 2003.

[39] R. Frischknecht and S. Büsser Knöpfel. Swiss Eco-Factors 2013 according to the Ecological Scarcity Method. Methodological fundamentals and their application in Switzerland. Technical report, Swiss Federal Office for the Environment, Bern, Switzerland, 2013.

[40] Léda Gerber and François Maréchal. Environomic optimal configurations of geothermal energy conversion systems: Application to the future construction of Enhanced Geothermal Systems in Switzerland. Energy, 45(1):908-923, September 2012.

[41] Victor Codina Gironès, Stefano Moret, Emanuela Peduzzi, Marco Nasato, and François Maréchal. Optimal use of biomass in large-scale energy systems: insights for energy policy. In 29th International Conference on Efficiency, Cost, Optimisation, Simulation and Environmental Impact of Energy Systems, Portoroz, Slovenia, 2016.

[42] Jani Lehto, Anja Oasmaa, Yrjö Solantausta, Matti Kytö, and David Chiaramonti. Review of fuel oil quality and combustion of fast pyrolysis bio-oils from lignocellulosic biomass. Applied Energy, 116:178-190, March 2014.

[43] Emanuela Peduzzi. Biomass To Liquids: Thermo-Economic Analysis and Multi-Objective Optimisation, $n^{\circ}$ 6529. PhD thesis, École Polytechnique Fédérale de Lausanne, 2015. 